Piotr Tomski ${ }^{l}$

\title{
SIEĆ SPOLECZNA PRZEDSIĘBIORCY W KULTURZE WSCHODNIEJ
}

\begin{abstract}
Streszczenie: Sieci społeczne dostarczają przedsiębiorcom szerokiego wachlarza wartościowych zasobów, wspierając ich w osiąganiu celów. Potencjał tkwiący w sieciach osobistych przedsiębiorcy to zasób szczególnych możliwości i czynnik wpływający w sposób pozytywny na efektywność przedsiębiorstwa. Analiza sieci osobistych przedsiębiorcy zdaje się być niepełna bez wskazania miejsca tego rodzaju sieci w kulturze Wschodu. W tej części świata sieci te zajmują bowiem istotną pozycję w codziennym życiu zarówno zwykłych ludzi, jak i przedsiębiorców. Celem niniejszego opracowania jest przedstawienie sieci społecznej i jej roli w kulturze wschodniej na przykładzie Chin.
\end{abstract}

Słowa kluczowe: sieć społeczna, sieć osobista, guanxi, efektywność, rozwój, przedsiębiorstwo, przedsiębiorczość

\section{Wstęp}

We współczesnej gospodarce ludzie stanowią strategiczne zasoby organizacji. Twierdzi się, iż przedsiębiorstwa będą w przyszłości odnosić sukcesy wyłącznie wtedy, gdy będą potrafiły zwiększać możliwości pracowników i aktywnie wspierać rozwój swojego potencjału ludzkiego [1]. Dotyczy to wszystkich przedsiębiorstw, włączając $\mathrm{W}$ to także podmioty ukierunkowane $\mathrm{W}$ swej działalności na procesy produkcyjne i ich doskonalenie. Ludzie zatem, jak podkreśla A. Pabian [2], stanowią, wręcz najważniejszy zasób każdej organizacji. Są oni włączani w produkcję oraz dystrybucję dóbr i usług, a zasoby ludzkie, które tworzą, obejmują wszystkich członków organizacji uszeregowanych od menedżerów najwyższego szczebla do pracowników wykonawczych.

Człowieka $\mathrm{w}$ organizacji oraz jego potencjał warto utożsamiać $\mathrm{z}$ osobą przedsiębiorcy, w rozumieniu zarówno przedsiębiorcy prowadzącego indywidualną działalność gospodarczą, jak i funkcjonującego w ramach większych podmiotów, realizującego proces intraprzedsiębiorczości. Warto zwrócić uwagę na znaczenie potencjału ludzkiego (potencjału przedsiębiorcy), utożsamianego $\mathrm{z}$ kapitałem społecznym, a precyzując problem, utożsamianego z sieciami powiązań, w których uczestniczy przedsiębiorca, dla funkcjonowania przedsiębiorstwa. Uczestnictwo w sieciach postrzegać należy jako niezwykle istotny obszar eksploracji zarówno w perspektywie teorii jak i praktyki przedsiębiorczości.

\footnotetext{
${ }^{1}$ dr hab. inż., Politechnika Częstochowska, piotr.tomski@wz.pcz.pl
} 
Sieć społeczna to struktura społeczna, tworzona przez zespół aktorów (np. ludzi, organizacji), połączonych siecią wzajemnych powiązań. Aktorzy połączeni są za pomocą więzi, które stanowią kategorię nadrzędną wobec relacji [3]. Współczesne przedsiębiorstwo określić można mianem obiektu umieszczonego $\mathrm{w}$ zachodzących na siebie i wzajemnie uzależnionych relacjach w układzie społecznym, ekonomicznym, przestrzennym, technologicznym i politycznym [4]. Analiza literatury przedmiotu skłania wręcz do stwierdzenia, iż sieci społeczne to kanwa dla struktur organizacyjnych wspomagających wszelką współpracę.

Sieci społeczne dostarczają przedsiębiorcom szerokiego wachlarza wartościowych zasobów, wspierając ich tym samym w osiąganiu celów postawionych przed zarządzanymi przez nich przedsiębiorstwami. Stwierdzić zatem należy, iż potencjał tkwiący $\mathrm{w}$ sieciach osobistych przedsiębiorcy to zasób szczególnych możliwości i czynnik oddziałujący $\mathrm{w}$ sposób pozytywny na efektywność przedsiębiorstwa. Kontakty przedsiębiorcy $\mathrm{z}$ aktorami pochodzącymi z jego otoczenia generują wartościowe, wielowątkowe informacje i wiedzę, które odpowiednio zinterpretowane $\mathrm{i}$ wykorzystane $\mathrm{w}$ procesie przedsiębiorczego zarządzania przyczyniają się do wzrostu wielowymiarowo postrzeganej efektywności firmy [5]. Sieć powiązań stanowi niewidoczną, potężną siłę, oferującą szerokie spektrum korzyści, związanych z różnymi aspektami funkcjonowania przedsiębiorstwa, tworząc w ten sposób sprzyjające warunki dla jego rozwoju [6].

Analiza sieci osobistych przedsiębiorcy zdaje się być niepełna bez wskazania miejsca tego rodzaju sieci w kulturze Wschodu. W tej części świata sieci te zajmują istotną pozycję w codziennym życiu zarówno zwykłych ludzi, jak i przedsiębiorców. Rozwój chińskiej gospodarki zaś skłania wielu autorów do podjęcia poszukiwań źródeł dynamicznego rozwoju przedsiębiorstw funkcjonujących w tej części świata. Wśród determinant rozwoju przedsiębiorstw wskazuje się często sieci osobiste, które określa się mianem guanxi.

Tak doniosła rola sieci społecznej przedsiębiorcy skłania do zainteresowania wykorzystaniem owych sieci w różnych warunkach społeczno-ekonomicznych, a tym samym w odmiennych lokalizacjach geograficznych i przy oddziaływaniu różnorodnych czynników kulturowych. W tych warunkach, celem niniejszego opracowania jest przedstawienie sieci społecznej i jej roli w kulturze wschodniej na przykładzie Chin.

\section{Istota guanxi}

Guanxi to koncepcja osobistych sieci społecznych w Chinach, szczególne sieci relacji i zależności międzyludzkich, wykorzystywanych w biznesie. Tworzone przez przedsiębiorców więzi $\mathrm{W}$ specyficzny sposób wykorzystywane są do 
prowadzenia działalności gospodarczej, poszukiwania i wykorzystywania szans oraz uruchamiania nowych przedsięwzięć.

Wyrażenie guanxi odnosi się do stanu zrelatywizowania, istniejącego między dwoma lub większą liczbą podmiotów, które mogą mieć charakter ożywiony bądź nieożywiony, abstrakcyjny bądź nieabstrakcyjny, być istotami ludzkimi lub nie. W przypadku menedżerów i przedsiębiorców, odnosi się do relacji międzyludzkich, stanowiących „specjalne koneksje osobiste” [7]. Tworzenie powiązań sieciowych guanxi jest jednym ze specyficznych zjawisk obserwowanych w działaniach strategicznych przedsiębiorstw funkcjonujących na rynku chińskim. Podobne relacje występują także w Japonii (kankei), Korei Południowej (kwankye) [15], a także Rosji (blat) [8].

W literaturze zidentyfikować można różnorodne konceptualizacje guanxi. Jest ono traktowane (odrębnie lub łącznie) jako: jednostki uczestniczące w relacjach oraz relacje tych jednostek [9], praktyki społeczne polegające na budowaniu i wykorzystaniu osobistych relacji, pozwalających sprostać wyzwaniom życia codziennego i zawodowego [10], strategia organizacji ukierunkowana na zdobywanie przewagi konkurencyjnej [11] oraz jako mechanizm kontraktowania i transakcji [12].

Zdaniem M.M. Yang [13], guanxi to powiązania, relacje i związki między pojedynczymi osobami, składające się na sieć wzajemnych zależności. W potocznym języku można by je określić jako „znajomości” lub „koneksje”. Owe relacje interpersonalne to specyficzny kapitał, gromadzony w długim okresie i wykorzystywany adekwatnie do potrzeb. Namnaża się on w wyniku istnienia wzajemnych uprzejmości i przysług, które tworzą wzajemne zależności. Więzi guanxi funkcjonują $\mathrm{w}$ różnych sferach życia, przyjmując charakter rodzinny, przyjacielski, polityczny czy biznesowy.

Powiązania guanxi charakteryzują się wysokim poziomem zaufania, który jest niezależny od otaczającej struktury społecznej [14]. Mają one charakter długofalowy, co implikuje jednocześnie brak właściwości zadaniowych. Strony w sieciach chińskich zainteresowane są kreowaniem trwałych i stosunkowo bliskich relacji, opartych na aksjomatycznym zaufaniu, generujących wartość dla wszystkich zaangażowanych stron. Ważny jest interes wspólnoty, nie zaś, jak w przypadku sieci zachodnich, interes jednostki. W sieciach zachodnich istotne jest zabezpieczenie interesów jednostki poprzez relacje kontraktowe, zarówno w krótkim, jak i długim horyzoncie czasowym. Wśród istotnych różnic J. Cygler [15] wymienia także charakter relacji. W przypadku guanxi mają one charakter niekomercyjny, istotne są relacje społeczne, mające silny wpływ na stosunki międzyorganizacyjne. $\mathrm{W}$ przeciwieństwie do tego stanu $\mathrm{w}$ kulturze zachodniej sieci mają charakter komercyjny i istotne są relacje biznesowe. $\mathrm{Z}$ punktu widzenia funkcjonowania relacji międzyorganizacyjnych ważna jest logika budowania relacji sieciowych. Warunkiem 
tworzenia sieci z inną organizacją jest budowa guanxi z jej menedżerami. W kulturze Zachodu zaś warunkiem dobrych relacji interpersonalnych $\mathrm{w}$ sieci są sukcesy związków międzyorganizacyjnych.

\section{Rola guanxi w kontekście zarządzania przedsiębiorstwem}

W badaniach prowadzonych nad guanxi zwraca się uwagę na jego rolę w kontekście biznesowym, co ma szczególne znaczenie zarówno w kontekście nauk o zarządzaniu jak i praktyki gospodarczej. Analiza dostępnych wyników badań pozwala sformułować wniosek, iż badacze podzieleni są na trzy grupy, dla których rola guanxi dla przedsięwzięć gospodarczych jest postrzegana odmiennie. Dla części badaczy guanxi przyczynia się do sukcesu organizacji [16], stanowiąc integralną część prowadzenia biznesu w Chinach, niezbędną na wszystkich etapach działań przedsiębiorstwa. Guanxi w tym ujęciu przyczynia się do redukcji kosztów transakcyjnych, niepewności, kosztów pozyskiwania informacji i zagrożeń dla konkurencyjności przedsiębiorstwa. Dodatkowo, guanxi zwiększa wsparcie instytucjonalne, dochody, efektywność biznesu i zdolność strategiczną. Druga grupa badaczy [17] postrzega guanxi jako wartościowy zasób, lecz tylko w niektórych obszarach działań biznesowych. W tym przypadku zwraca się szczególną uwagę na wsparcie wchodzenia przedsiębiorstwa na rynek, obniżenie kosztów transakcyjnych i ułatwienie działania przedsiębiorstwa w związku z zapewnieniem zasobów i informacji. Trzecia grupa badaczy [18] podkreśla zmniejszającą się rolę guanxi $\mathrm{w}$ prowadzeniu biznesu, uważając jednocześnie, iż opisywane w literaturze korzyści płynące z guanxi są wyolbrzymiane. W tym ujęciu twierdzi się, iż relacje są istotne dla prowadzenia biznesu niezależnie od miejsca, zaś produkt i cena są wiodącymi determinantami wyboru partnera, w tym dostawcy. Ponadto, rozwijanie i utrzymywanie więzi guanxi wymaga poświęcenia czasu, zasobów, generując dodatkowe koszty. Czynniki te zatem mogą stać się obciążeniem zamiast korzyścią, szczególnie w obszarze dążenia do obniżenia kosztów transakcyjnych [19]. W badaniach pojawia się także wątek małych przedsiębiorstw, które nie posiadając odpowiednich więzi guanxi mogą doświadczać problemów wynikających w szczególności z niedostatecznego wsparcia ze strony władz [20].

W literaturze zwraca się uwagę, iż globalizacja wykreowała czynniki stymulujące oraz jednocześnie wygenerowała specyficzną presję na chińskie organizacje, które powinny rozszerzać efektywność biznesową oraz środowiskową. Dostępne wyniki badań wskazują jednocześnie, iż właśnie istnienie guanxi między partnerami organizacyjnymi przyczynia się do 
wzmocnienia pozytywnego efektu realizowanych praktyk w zakresie ekologii i szczupłego zarządzania [21].

W kontekście powyższych rozważań warto przytoczyć pracę K. Obłoja i S. Zhanga [22], którzy nawiązują do guanxi w ramach prezentacji wyników badań z obszaru dominującej logiki chińskich przedsiębiorców. Dominująca logika firmy stała się jednym z najważniejszych problemów badawczych na styku przedsiębiorczości i zarządzania strategicznego. Jest to wzorzec, będący „strategiczną ramą", która jest odzwierciedleniem teorii biznesu, własnego sposobu postrzegania otoczenia i firmy, przyjętych i powielanych wzorców działania. Poszukiwanie dominującej logiki firmy ma swoje zakorzenienie filozoficzne i związane jest z pytaniami o habitus, czyli struktury poznania i motywacji - uniwersalne mechanizmy, które w sposób naturalny i zwykle nieświadomy stosowane są przez jednostki, aby wyjaśnić, zrozumieć i ostatecznie zaakceptować otaczający świat [23]. K. Obłój także zwraca uwagę, iż kapitał społeczny, rozumiany jako guanxi, jest uznawany przez część badaczy za ważny i niepowtarzalny chiński aspekt przedsiębiorczości. Kapitał relacji i powiązań guanxi jest uważany za najbardziej znaczącą cechę kultury chińskiego biznesu i bardzo ważny niematerialny zasób sprzyjający sukcesom nowych przedsięwzięć. Badania jakościowe przeprowadzone przez K. Obłoja i Z. Zhanga $\mathrm{w}$ chińskich przedsiębiorstwach potwierdzają, iż przedsiębiorcy zgadzają się z opinią, że relacje, układy i powiązania są zasobem, lecz podzieleni są co do jego rzeczywistej wartości biznesowej. Część przedsiębiorców uznaje, iż jest to zasób ważny, jednak nieefektywny, o ograniczonej wartości.

W krajach rozwijających się, w których formalne wsparcie instytucjonalne jest często niewystarczające, istotną rolę odgrywają relacje nieformalne. W kulturze chińskiej typową formą takich relacji jest właśnie guanxi [24]. W odniesieniu do społeczeństwa chińskiego można stwierdzić, że w porównaniu ze społeczeństwami Zachodu charakteryzuje się silnym poczuciem wspólnoty. Znajduje to swoje odzwierciedlenie w konkretnych działaniach realizowanych na poziomie jednostki, a także chińskich przedsiębiorców, stosujących specyficzną strategię budowania więzi interpersonalnych guanxi [25]. Choć budowanie sieci relacji interpersonalnych cechuje wszystkie kultury, strategia wykorzystywania wzajemności i zobowiązań opartych na bezpośrednich kontaktach międzyludzkich ma w kulturze chińskiej swą szczególną specyfikę, polegającą na powszechności tego zjawiska oraz częstym postrzeganiu go jako kluczowy kapitał wykorzystywany w działalności gospodarczej [26]. W literaturze poświęconej sieciom społecznym wskazuje, że w przypadku zachodnich organizacji, 
budowanie relacji guanxi stanowi efektywny sposób redukowania ciężaru "zagraniczności" czy wręcz "obcości" w odniesieniu do chińskiego rynku. Związane jest to $\mathrm{z}$ faktem, iż guanxi postrzegane jest jako nieformalny proces wykorzystywany do budowania zaufania między jednostkami, które przyczynia się do redukcji niepewności związanej z wykonywaniem umów [27].

\section{Podsumowanie}

Choć kultura prowadzenia biznesu w warunkach polskich jest odmienna, brak przyjaznych biznesowi ram instytucjonalnych oraz brak wsparcia ze strony rządu, a nawet utrudnianie i piętnowanie przedsiębiorczości w okresie przed wprowadzeniem ustawy o swobodzie działalności gospodarczej, także w Polsce doprowadziły do rozwoju kontaktów i „układów”, których zadaniem było wspieranie realizacji przedsięwzięć o charakterze gospodarczym. W tym kontekście może pojawić się zatem pytanie, czy i w jakim stopniu specyfika owych trudnych dla przedsiębiorców czasów wywarła wpływ na sposób prowadzenia działalności w Polsce w XXI wieku oraz czy 25 lat po wprowadzeniu ustawy deklarującej wsparcie dla small biznesu znajomości i nieformalne relacje międzyludzkie, w których uczestniczy przedsiębiorca, są ważne, przez jakie zmienne moderowany jest rezultat ich działania oraz jakie grupy $w$ ramach sieci społecznych przedsiębiorców są najczęstszym źródłem szans przedsiębiorczych i innych sygnałów wykorzystywanych w praktyce zarządzania [28].

Reasumując rozważania zaprezentowane w niniejszym opracowaniu, stwierdzić należy, że analiza współczesnych studiów nad funkcjonowaniem przedsiębiorstw wskazuje na rosnącą liczbę badań i publikacji poświęconych wpływowi więzi międzyludzkich na funkcjonowanie biznesu, w tym więzi o charakterze nieformalnym, których odpowiednikiem jest guanxi w kulturze wschodniej. W literaturze często podkreśla się, że przedsiębiorcy wykorzystują osobiste sieci powiązań międzyludzkich (sieci społeczne), zarówno o charakterze prywatnym, jak i biznesowym, do pozyskiwania zasobów i informacji, które nie byłyby osiągalne przy wykorzystaniu mechanizmu rynkowego lub pozyskanie ich wiązałoby się z wyższymi kosztami. Niezwykle istotnym aspektem znaczenia sieci społecznych dla funkcjonowania przedsiębiorstw jest także fakt, iż sieci te wpływają również na sposób prowadzenia biznesu przez przedsiębiorcę oraz orientację przedsiębiorczą na poziomie indywidualnym. Sieci te zatem wpływają na rozumowanie firm zaangażowanych $\mathrm{w}$ tworzenie nowych przedsięwzięć, a także myślenie dojrzałych podmiotów kontynuujących realizację dotychczasowych 
przedsięwzięć, których sposób działania ukonstytuowany został właśnie w oparciu o osnowę ukształtowaną z sieci społecznych.

\section{Bibliografia}

[1] Penc J. Humanistyczne wartości zarzadzania w poszukiwaniu sensu menedżerskich działań, Difin, Warszawa 2010, s. 93-94.

[2] Pabian A. "Sustainable personel-pracownicy przedsiębiorstwa przyszłości." Zarzadzanie Zasobami Ludzkimi 5, s. 9-27, 2011.

[3] Olesiński Z. Zarządzanie relacjami międzyorganizacyjnymi, Wydawnictwo C.H. Beck, Warszawa 2010.

[4] Nogalski B., Niewiadomski P. 2014. "Dopasowanie zasobowe jako warunek elastyczności produktowej i determinanta konkurencyjności zakładu wytwórczego ocena istotności wymagań", [w:] J. Stachowicz, M. Nowicka-Skowron, L.A. Voronina (red.), Rozwój organizacji $i$ regionu wyzwaniem dla ekonomii $i$ nauk o zarządzaniu, Wydawnictwo „Dom Organizatora”, Toruń 2014, s. 225-249,

[5] Tomski P., Sieć społeczna jako potencjał przedsiębiorcy determinujący efektywność firmy, QUALITY PRODUCTION IMPROVEMENT No. 2(7), s. 81-93, 2017.

[6] Gudkova S. "Sieć osobistych powiązań - źródło przewagi małych przedsiębiorstw na rynku", Problemy Zarzadzania, 1, s. 68-86, 2007.

[7] Chen C.C., Chen X., Huang S. "Chinese Guanxi: An Integrative Review and New Directions for Future Research", Management \& Organization Review, 9(1), s. 167207, 2013.

[8] Michailova S., Worm V. "Personal Networking in Russia and China: Blat and Guanxi", European Management Journal, 4(21), s. 509-519, 2003.

[9] Tsui A.S., Farh J. -L. "Where guanxi matters: Relational demography and guanxi in the Chinese context". Work and Occupations, 24(1), s. 56-79, 1997.

[10]Chen C.C., Chen Y.R., Xin K. "Guanxi practices and trust in management: A procedural justice perspective". Organization Science, 15(2), s. 200-209, 2004.

[11]Li J.J., Poppo L., Zhou K. "Do managerial ties in China always produce value? Competition, uncertainty, and domestic vs. foreign firms". Strategic Management Journal, 29(4), s. 383-400, 2008.

[12]Lovett S., Simmons L.C., Kali R. "Guanxi versus the market: Ethics and efficiency". Journal of International Business Studies, 30(2), s. 231-247, 1999.

[13]Yang M.M. Gifts, Favours and Banquets: the Art of Social Relationships in China, Cornell University Press, Ithaca 1994.

[14]Burt, R. S., Bian, Y., \& Opper, S. "More or less guanxi: Trust is $60 \%$ network context, 10\% individual difference". Social Networks, 54, s. 12-25, 2018.

[15]Cygler J. "Guanxi - chińska koncepcja sieci". Przegląd Organizacji, 6, s. 14-18, 2011.

[16]Luo Y. Guanxi and Business, World Scientific Publishing, Singapore 2007.

[17]Clegg S., Wang K., Berrell M. Business networks and Strategic Alliances in China, Edward Elgar Publishing Limited, MPG books Ltd, Bodmin, Cornwall 2007.

[18]Guthrie D. Information asymmetries and the problem of perception: the significance of structural position in assessing the importance of guanxi in China, Social Connections in China; Institutions, Culture, and the changing Nature of Guanxi, Cambridge University Press, Cambridge 2002. 
[19]Fock K.Y., Woo K. "The China market: strategic implications of guanxi". Business Strategy Review, 7(4), s. 33-44, 1998.

[20]Guthrie D. Information asymmetries and the problem of perception: the significance of structural position in assessing the importance of guanxi in China, Social Connections in China; Institutions, Culture, and the changing Nature of Guanxi, Cambridge University Press, Cambridge 2002.

[21]Zhan, Y., Tan, K. H., Ji, G., Chung, L., \& Chiu, A. S. "Green and lean sustainable development path in China: Guanxi, practices and performance". Resources, Conservation and Recycling, 128, s. 240-249, 2018.

[22]Obłój K., Zhang S. "Przekraczaj rzekę po kamieniach: analiza dominującej logiki chińskich przedsiębiorców", Master of Business Administration, 2(112), s. 43-53, 2011.

[23] Obłój K. Przedmowa, [w:] K. Obłój (red.), Dominujaca logika firmy, Wydawnictwo Wyższej Szkoły Przedsiębiorczości i Zarządzania im. Leona Koźmińskiego, Warszawa 2003.

[24] Wąsowska A. Umiędzynarodowienie firm z krajów rozwijajacych się - rola sieci spotecznych, [w:] M. Cisek (red.), Kapitat relacyjny w nowoczesnej gospodarce, Wydawnictwo Studio Emka, Warszawa 2009.

[25]Bąkiewicz A. Strukturalne aspekty rozwoju gospodarczego. Doświadczenia azjatyckie, Wydawnictwo Uniwersytetu Warszawskiego, Warszawa 2010.

[26]Bąkiewicz A. Kulturowe uwarunkowania biznesu rodzinnego w Chinach, Przedsiębiorczość i Zarządzanie, Wydawnictwo SAN, Tom XV, Zeszyt 7, Część III, s. 37-48, 2014.

[27]Guo, Y., Rammal, H. G., Benson, J., Zhu, Y., Dowling, P.J. "Interpersonal relations in China: Expatriates' perspective on the development and use of guanxi". International Business Review, 27(2), s. 455-464, 2018.

[28]Tomski P. Sieć spoleczna przedsiębiorcy w teorii i praktyce zarzadzania mała firma, Wyd. Wydziału Zarządzania Politechniki Częstochowskiej, Częstochowa 2016.

\title{
THE ENTREPRENUER'S SOCIAL NETWORK IN EASTERN CULTURE
}

\begin{abstract}
Social networks provide entrepreneurs with a wide range of valuable resources, supporting them in achieving objectives. The potential of the entrepreneur's personal networks is the resource of specific opportunities positively affecting the performance of the company. The analysis of personal networks of the entrepreneur seems to be incomplete while not indicating the place of this type of network in Eastern culture since, in this part of the world, they occupy a significant position in everyday life of both ordinary people and entrepreneurs. The objective of the present study is the presentation of the social network and its role in Eastern culture on the example of China.
\end{abstract}

Key words: social network, personal network, guanxi, performance, enterprise, entrepreneurship

Data przesłania publikacji do Redakcji: 26.06.2018

Data akceptacji publikacji przez Redakcję: 24.07.2018 
